\title{
Development of a DC-Plasma Torch Constructed with Graphite Electrodes and an Integrated Nebulization System for Decomposition of $\mathrm{CCl}_{4}$
}

\author{
Anelise L.V. Cubas, Eduardo Carasek, Nito A. Debacher* and Ivan G. de Souza \\ Departamento de Química, Universidade Federal de Santa Catarina, 88040-900 Florianópolis-SC, Brazil
}

\begin{abstract}
O presente trabalho consiste no desenvolvimento de uma tocha de plasma de corrente contínua com eletrodos de grafite e sistema de nebulização integrada para a eliminação de resíduos líquidos organoclorados (tetracloreto de carbono) em pequena escala. Os gases resultantes da pirólise do tetracloreto de carbono pelo plasma foram coletados e identificados por cromatografia gasosa acoplada ao espectrômetro de massa (GC-MS) e monitorados por cromatografia gasosa com detecção por ionização de chama (GC-FID). Observou-se que a tecnologia do plasma térmico elimina tetracloreto de carbono, caracterizando-se por baixo custo, simplicidade operacional e dimensões reduzidas, apresentando-se como uma alternativa ambientalmente correta, pois reduz a emissão total de gases organoclorados.
\end{abstract}

This work describes the development of a continuous flow plasma torch with graphite electrodes and an integrated nebulization system for the elimination of organochlorine liquid waste (carbon tetrachloride) on a small scale. The gases resulting from the pyrolysis of the carbon tetrachloride by the plasma were collected and identified by gas chromatography, coupled with mass spectrometry (GC-MS). Monitoring was carried out by gas chromotography with flame ionization detection (GCFID). It was observed that the thermal plasma technique eliminated the carbon tetrachloride completely, being characterized by low cost, operational simplicity and reduced dimensions. This technique presents a suitable environmentally correct alternative, since it reduces the total emission of organochlorine gases.

Keywords: waste treatment, organochlorines, DC-plasma torch

\section{Introduction}

The chemical wastes generated by laboratories at universities and research institutions are noted for their great diversity and small quantities in relation to the hazardous waste generated by industries. These characteristics make their treatment much more difficult, since the employment of large incineration plants involving thermal processes is not economically viable for the incineration of hazardous waste in small quantities and variable chemical composition.

Technologies involving thermal processes have been extensively used in the treatment of chemical wastes. The oldest and best known is incineration in which the waste is converted through oxidation, into a material which is less voluminous and more inert than the original. ${ }^{1}$ However, in the case of hazardous chemical wastes such as organochlorines, apart from the incineration furnaces, the

* e-mail: debacher@qmc.ufsc.br system requires expensive gas washing towers for the retention of dioxins and furans (carcinogenic organochlorines produced mainly by the incineration of chloride compounds), ${ }^{1}$ generated by incomplete oxidation. Despite being generally efficient, treatment by incineration does not provide a final solution for the dioxins and furans that remain deposited in the hydraulic washing system or are released directly into the atmosphere. ${ }^{2}$

A new and very attractive process as a final treatment of this class of chemical waste is pyrolysis by thermal plasma. ${ }^{3}$ Due to the high temperature and the absence of oxygen in the process, ${ }^{2}$ which minimizes the possibility of forming toxic compounds such as dioxins and furans, this technology offers considerable advantages in comparison to ordinary processes of thermal oxidation.

In recent years a wide amount of research concerning the destruction of hazardous wastes using plasma torches has been conducted. Such studies report the treatment of organochlorine residues by thermal plasma, ${ }^{4-11}$ describing the removal efficiency of the compounds, torch efficiency, 
treatment time, operational costs and absence of dioxins and furans in the resulting pyrolytic gases.

Our research aimed to develop a compact system for the elimination of carbon tetrachloride waste employing the plasma process. This involved the planning and construction of a system for the pyrolysis of carbon tetrachloride and analysis of gases produced, applying a pre-concentration procedure, the solid-phase microextraction system (SPME). The compounds formed by thermal pyrolysis were identified using gas chromatography with flame ionization detection (GC-FID) and gas chromatography coupled with mass spectrometry (GC-MS).

\section{Materials and Methods}

The experimental section consists of two parts. The first describes the construction and optimization of the graphite electrode plasma torch. The second part describes the resulting gases from the pyrolysis of the carbon tetrachloride, which were analyzed by GC-MS and GCFID, using the SPME pre-concentration technique. The presence of solid carbon was confirmed by SEM (Scanning Electron Microscopy) and the presence of chlorine was confirmed by the silver nitrate test.

\section{Graphite electrode plasma torch}

The configuration of the graphite electrode plasma torch employed was similar to that proposed by Margoshes and Scribner, ${ }^{12}$ being composed of two graphite electrodes coupled with a pneumatic nebulizer, as shown in Figure 1. The Margoshes torch was originally developed for spectroscopic chemical analysis. However, our proposed system was for the elimination of organochlorine liquid waste. The design of this torch employed materials such as Bakelite and Teflon instead of metal and hard rubber as proposed by Margoshes. These materials were chosen because of their excellent thermal and electrical insulation properties. In addition, these materials are easily found in local commerce and are good for mechanical works. The dimensions of our torch were modified to increase the nebulization efficiency, and the construction was carried out in the mechanical workshop of our own Chemistry Department (UFSC). The following working specifications were applied: inter-electrode distance $2 \mathrm{~mm}$, current $80 \mathrm{~A}$, liquid sample flow $2.0 \times 10^{-2} \mathrm{~L} \mathrm{~min}^{-1}$, argon flow for the plasma formation $7 \mathrm{~L} \mathrm{~min}^{-1}$, auxiliary argon flow for the nebulization $5 \mathrm{~L} \mathrm{~min}^{-1}$.

These were the optimal conditions to guarantee that all the nebulized material underwent pyrolysis inside the

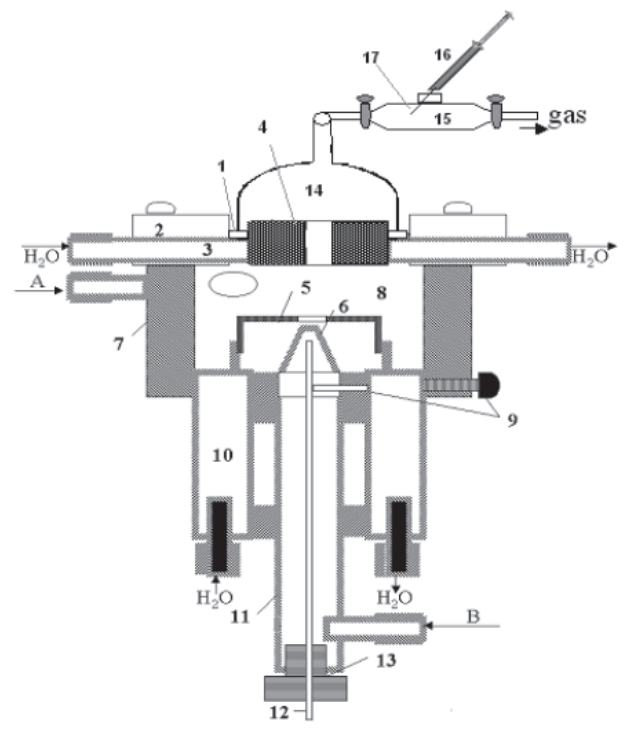

Figure 1. Graphite electrode torch. 1-Fitting for the gas collection system; 2-Support Grips; 3-Cooled brass disc; 4-Cathode; 5-Anode; 6-Atomizer spout; 7-Bakelite cylinder; 8-Chamber; 9-Screw; 10cooled brass cylinder; 11-Atomizer; 12-Stainless steel capillary tube for liquid sample; 13-Teflon screw; 14-Post-pirolysis chamber; 15sampling ampoule; 16-micro syringe; 17-PDMS fiber. A: Main argon entrance; B: Auxiliary argon entrance.

torch. Argon was used to form the plasma torch on account of its low thermal conductivity ${ }^{13}$ and its low energy required for ionization. In our system the energy required was 3.2 Kw. Other gases could be used for plasma generation, such as helium, nitrogen and oxigen. Measurements taken by Weiss, ${ }^{13}$ using an argon plasma jet with cooled water at a current of 50 - $1400 \mathrm{~A}$ and various cathode apertures, showed temperatures of around $10000^{\circ} \mathrm{C}$ for conditions similar to those used in our study.

\section{Working mechanism}

The formation of the plasma was established between the cathode (4) and the anode (5), under a difference in potential and current between them of around $40 \mathrm{~V} / 80 \mathrm{~A}$. The direct current source for the generation and maintenance of the plasma torch was a transformer reductor and a change intensity current reactor with rectifiers and filters connected in a bridge-type circuit. The arc was initiated by the discharge of a momentary spark of a circuit incorporated in the direct current source. Argon was the gas used to form the plasma. The main $\operatorname{argon}$ stream (A) for the plasma formation was introduced helically into the chamber (8) with a flow of $7 \mathrm{~L} \mathrm{~min}^{-1}$. The zone of pyrolysis became stabilized between the cathode and the anode. The auxiliary argon stream (B) was used to carry and nebulize liquid materials into the hot plasma torch through a stainless steel capillary tube (12). This auxiliary argon 
stream was also used to carry the pyrolyzed products outside the plasma chamber.

The cathode (4) was a $12 \mathrm{~mm}$ graphite disc with a central orifice of $1 \mathrm{~mm}$, which was fitted into the center of the watercooled brass disc (3) and held with supporting grips (2) to a Bakelite cylinder (7) used as a thermal and electric insulator for the anode. The anode (5), which was also made of graphite and had the same dimensions as the cathode, was held at the tip of the water-cooled brass cylinder (10) fitted to the Bakelite cylinder. The Teflon atomizer (11) with a graphite spout (6) was screwed into the brass cylinder. The stainless steel capillary tube, (12) for the sample injection, was held inside the atomizer by a Teflon screw. Brass screws connected both anode and cathode. The gas resulting from the pyrolysis was collected in the gas sampling system, which was fixed to the torch (1) with a rubber tube in the upper part of the brass disc (3). The gas sampling system (Figure 1) for collecting pyrolysed products was made up of a quartz waterrefrigerated post-pyrolysis chamber (14) and a sampling ampoule (15). The solid carbon produced was trapped on the wall of the post-pyrolysis chamber. The gas was retained in the ampoule by rotation joint taps at its extremities. The gas sample was collected via the needle of the micro syringe (16) from the septum in the central opening of the ampoule by means of the fiber (17) covered with the polymer polydimethylsiloxane (PDMS) of $100 \mu \mathrm{m}$ thickness. After each procedure to eliminate $\mathrm{CCl}_{4}$ was carried out, the torch was cleaned because of accumulation of soot from decomposition of $\mathrm{CCl}_{4}$ and from the graphite electrode.

\section{Analytical procedures}

The carbon tetrachloride sample was submitted to the plasma at various entry rates $\left(0.2 \times 10^{-3}, 0.3 \times 10^{-3}\right.$ and $0.4 \times$ $10^{-3} \mathrm{~L} \mathrm{~min}^{-1}$ ) and the gases generated were analyzed. The analysis of gas products was conducted by the SPME technique. In this process, gases were collected in the sampler ampoule, where a PDMS polymer fiber was exposed for 30 min. During this period, the analytes were absorbed onto the fiber and later were desorbed in the heated injector of the gas chromatograph, providing a chromatogram of the compounds resulting from the pyrolysis. The analyses were carried out on a Shimadzu gas chromatograph, model GC14B, equipped with a flame ionization detector (FID) and split/splitless injector and with detection by mass spectrometry (GC-MS) model 14A, QP-2000A.

\section{Results and Discussion}

In theory, when carbon tetrachloride is injected directly into the plasma torch, the high density of energy generated by this procedure breaks the molecular structure of the individual components into their constituent atoms. ${ }^{14}$ The blackening of the post-pyrolysis chamber indicates the formation of solid carbon by the process. Analysis of these solids by SEM also confirms the presence of solid carbon and adsorbed chlorine. The pyrolysis gases, when bubbled through an aqueous acid medium, also confirm the presence of chlorine by the silver nitrate test. Data from the literature confirm ${ }^{15}$ that the pyrolysis of $\mathrm{CCl}_{4}$ can also produce chlorine gas $\left(\mathrm{Cl}_{2}\right)$ and solid carbon $(\mathrm{C})$.

Because of the high dilution factor present in the gaseous sample, constituted mainly by chlorine and argon, and due to a very low number of gaseous products generated by the process, the use of an airtight syringe to monitor the gas products formed in thermal plasma pyrolysis is not adequate for GC-MS analysis. In this sense, the use of the SPME technique for the pre-concentration and monitoring of gases deriving from thermal plasma showed to be a powerful tool when compared with the airtight syringe ${ }^{16}$. Then, the analysis of gases deriving from destruction of $\mathrm{CCl}_{4}$ by thermal plasma using SPME technique was achieved, and peaks of the byproducts formed were observed on the chromatograms as shown in Figure 2. In these chromatograms, the peaks with a retention time of 1.6 min correspond to carbon tetrachloride. The analysis of the chromatograms also revealed peaks with retention times greater than those of $\mathrm{CCl}_{4}$, which characterizes compounds of greater molecular mass than carbon tetrachloride. Tests using GC-MS allowed the following attributions: tetrachloroethylene; hexachloro-ethane; 1,1,2,3,4,4 hexachloro 1,3-butadiene; hexachlorobenzene and 1,2,3,4-tetrachloro 5-dichloro 1,3-cyclopentadiene.

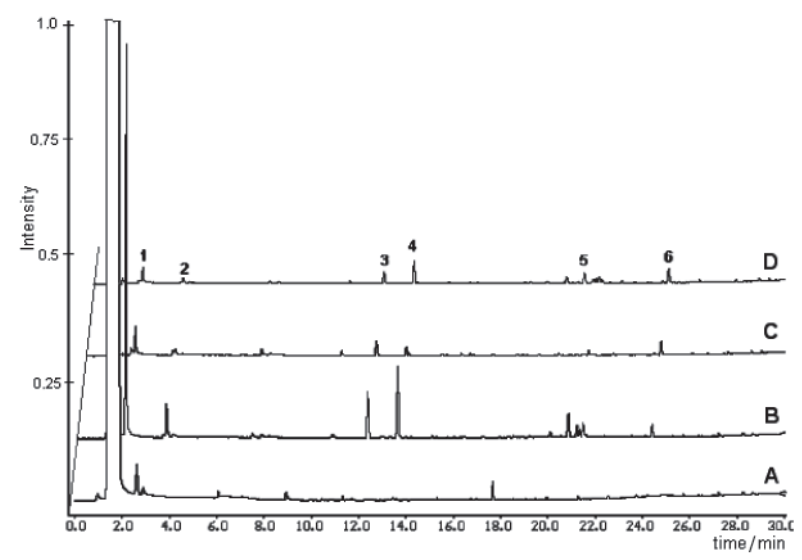

Figure 2. Chromatograms of the gases resulting from the pyrolysis after SPME extraction for different sample entry flow rates. A: Blank of carbon tetrachloride; B: $0.4 \mathrm{~mL} \mathrm{~min}^{-1}$; C: $0.3 \mathrm{~mL} \mathrm{~min}^{-1}$; D: $0.2 \mathrm{~mL}$ $\mathrm{min}^{-1}$. Peaks 1: carbon tetrachloride; 2: tetrachloroethylene; 3 : Hexachloro-ethane; 4: 1,1,2,3,4,4 - hexachloro-1,3-butadiene; 5: hexachlorobenzeno; 6: 1,2,3,4 - tetrachloro 5-dichloro 1,3cyclopentadiene. 
Structurally, the solid carbon is constituted by carbon atoms linked in hexagonal planes, which form layers that are easily removed from the body of the solid. Each carbon atom is bound to another three via one double and two single bonds. In this way, the presence of solid carbon, chlorine ions, high temperature and a reduced atmosphere rich in electrons explains the formation of these compounds. ${ }^{14,15,17}$

The peak intensity of carbon tetrachloride was used to obtain the destruction and removal efficiency of this compound by the homemade plasma torch (Figure 2). Therefore, the study of efficiency was calculated as the ratio between the $\mathrm{CCl}_{4}$ chromatography signal obtained with the thermal plasma turned-off and the $\mathrm{CCl}_{4}$ chromatography signal with the thermal plasma turnedon. The presence of the carbon tetrachloride peaks on the chromatograms obtained when a high flow rate of liquid sample was used showed an incomplete pyrolysis of $\mathrm{CCl}_{4}$. The ideal aspiration rate of the sample for maintaining equilibrium between the aerosols formed and the plasma to obtain a complete pyrolysis was found at $0.2 \mathrm{~mL} \mathrm{~min}^{-1}$.

The efficiency of the decomposition of $\mathrm{CCl}_{4}$ using the homemade torch to generate thermal plasma can be demonstrated by the major solid carbon and chlorine and minor chlorinated compounds detected in the postpirolysis chamber. Its efficiency was $98 \%$ using its optimized operational conditions and this result is in agreement with those published by Staley ${ }^{15}$ and Han et $a l .{ }^{7}$ who obtained efficiencies between $93 \%$ and $99.9 \%$.

\section{Conclusions}

With a view to providing a solution for the liquid organochlorine waste generated in teaching and research laboratories and based on the modern technology of plasma, it may be said that the system proposed here is characterized by low cost and operational simplicity. The reduced dimensions of the plasma torch and the treatment time are also smaller than conventional incineration techniques. ${ }^{18}$ The aspiration rate $\left(2.0 \times 10^{-2} \mathrm{~L}, \mathrm{~min}^{-1}\right)$ could be increased by employing systems with various torches in series. The graphite electrodes may cause high erosion rates and require more frequent replacement, ${ }^{19}$ although graphite is a low-cost and easily applicable material.

This work confirms that the homemade plasma torch can be used to decompose chlorinated material, reducing the total emission of gases and also favoring the viability of mobile equipment for the treatment of liquid residues on a small scale.

\section{Acknowledgements}

A.L.V. Cubas thanks the Conselho Nacional de Desenvolvimento Científico e Tecnológico (CNPq) for her doctorate fellowship. All authors would also like to acknowledge the instrumental support provided by the Central de Análises of the Departamento de Química UFSC.

\section{References}

1. Manahan, S.E.; Manahan, S.E.; Fundamentals of Environmental Chemistry; $2^{\text {nd }}$ ed., CRC Press: Florida, 2001.

2. Baird, C.; Environmental Chemistry, W.H. Freeman and Company: New York, 2000.

3. Menezes, R.A.A.; Bessa, I.; Menezes, M.A.; Seminário de Meio Ambiente. ABM-Associação Brasileira de Metalurgia e Materiais, São Paulo, 1999; http://www.kompac.com.br/ publicacoes/index.html, accessed in February 2005.

4. Kim S.W.; Park, H.S.; Kim, H.J.; Vacuum. 2002, 70, 59

5. Wang, Y.A.; Lee W.J.; Chen, C.Y.; Hsieh, L.T.; Environ. Sci. Technol. 1999, 33, 2234.

6. Kostic, Z.G.; Stefanovic, P.L.J.; Pavlovic, P.B.; J. Hazard Mater. 2000, 75, 75.

7. Han, Q.Y.; Heberlein, J.; Pfender, E.; J. Mater. Synth. Proc. 1993, 1,25

8. Sekiguchi, H.; Honda, A.T.; Kanzawa, A.; Plasma Chem. Plasma Process. 1993, 13, 463.

9. Inaba, T.; Iwao, T.; IEEE Trans. Dielec. Elec. Insulation 2000 , 7, 684

10. Han, Q.Y.; Zhuang, Q.D.; Heberlein, J.V.R.; Tormanen, W.; Emerging Technologies in Hazardous Waste Management, ACS Symp. Ser. 1995, 11, 135.

11. Staley, L.J.; Environ. Sci. Technol. 1990, 3, 67.

12. Margoshes, M.; Scribner, B.F.; Spectrochim. Acta 1959, 15, 288.

13. Weiss, R.; Zeitschrift fur Physik. 1954,138, 170.

14. Gupta, A.K.; J. Propul. Power 2000, 16, 615.

15. Staley, L.J.; J. Hazard. Mater. Control 1990, 3, 67.

16. Cubas, A.L.V.; Carasek, E.; Debacher, N.A.; de Souza, I.G.; Chromatographia 2004, 60, 85.

17. Freeman, H.M; Olexsey, R.A; Oberacker, D.A; Mournighan, R.E. J. Hazard Mat. 1987, 14, 103.

18. Smith, E.D.; Zaghloul, H.; Arnold, J.I.; Kanaras, L.; Civil Eng. 1997, 67, 34.

19. Bonizzoni, G.; Vassallo, E.; Vacuum 2003, 70, 59

Received: January 29, 2004 Published on the web: February 28, 2005 